\title{
A MODEL FOR BUILDING SOCIAL COMPETENCES IN THE TEACHING OF ENVIRONMENTAL SCIENCE IN THE PRIMARY SCHOOL STAGE OF EDUCATION Vanya Petrova ${ }^{1}$
}

\begin{abstract}
In the new requirements for general education in Bulgaria from 2015 and in the new curricula in Environmental Science in $1^{\text {st }}$ and $2^{\text {nd }}$ grade, social competence is highlighted as an important element of the formative functions of education.

In the presented model for Environmental Science teaching during the primary stage of education, it is built as a complex perspective in the development of the student, passing through the whole content and technology of the pedagogical progress. The most important features of this model are the enhanced emotional and value related side in determining the goals of education and pedagogical technology based on the proactive participation of the student and sustainable tools of interactive methods and techniques.
\end{abstract}

The model is set in two school kits consisting of an educational textbook and workbook in Environmental Science - for the $1^{\text {st }}$ and $2^{\text {nd }}$ grade which are currently used in Bulgarian Education.

UDC Classification: 37.01. , DOI: https://doi.org/10.12955/pss.v1.69

Keywords: competence, social competence, curricula in Environmental Science

\section{Introduction}

The issue concerning social competences has become relevant to the acceptance of key competences for Lifelong learning following the European commission model.

While in the last century the concept of social competence has been applied to different aspects of psychosocial functioning of the individual, at the beginning of the $21^{\text {st }}$ century this concept is now considered as a basic activity in all spheres of life.

This study's aim is to trace the highlights of the competence approach accents in the implementation of the new curriculum (an enhanced emotional and values related part in determining the purpose of training and educational technology) and to outline the substantive and methodical characteristics of building social competencies through Environmental Science teaching in the 1st and 2nd grades by using two school kits consisting of a notebook and a textbook (Petrova, Janakieva, Parvanova, Stoyanova, 2016, 2017).

\section{Literature review}

Anderson \& Messik (1976) note that the so-called social competence panel can be formed with 29 areas of competences included.

According to D. Levterova et al. (2009) “The process of formation of a person's social competence deploys throughout the life. It starts from the family, continues in the periods of study in the different levels of education, during the professional improvement process and social contacts created by persons throughout their life" (p. 69). According to the above-mentioned author, forming social competence includes:

- building social skills from an early age;

- formation through teaching and training - tools;

- "self-fulfilling prophecies effect";

- cognitive and socio-informational processes.

The teaching of Environmental Science $\left(1^{\text {st }}\right.$ and $2^{\text {nd }}$ grade $)$ in primary school achieves all indicated trends of forming social competence. The grounds for such conclusion are as follows:

1. In the targeted and contented elements of the curriculum the social communities and relations of the child are highlighted and focus on a strongly expressed educational character.

2. The new Environmental Science curricula for the $1^{\text {st }}$ and $2^{\text {nd }}$ grade are a foundation of a pedagogical and methodical model for designing a teaching process where the child is a participant and a driving force of their education, tutoring and development.

3. The curricula are unloaded in terms of information but they are further developed in the formative aspects of Environmental Science teaching.

\footnotetext{
${ }^{1}$ Faculty of Education, Trakia University, Stara Zagora, Bulgaria, vanja_p@abv.bg
} 
4. Relations in the studied communities are considered in a positive emotional and values related approach.

5. The category "competence" itself is for the first time a key element in the curricula and it forms a significant part of the design and focus of the new curricula.

In the Environmental Science curriculum, the term competence is present in the following context: As defining the content differentiation of the educational content in separate "areas of competence". Based on this new approach, the areas of competences needed for a respective age are outlined by overcoming a meaningful information order of structuring. As expected results on global issues - in this element of the curriculum set of competencies have been defined. They are consistent with the age of the students' capacities in the primary school, and preclude memorizing and mechanical reproduction suggesting the involvement of children on the cognitive level that they have mastered.

Competence building has a highly integrative nature. As Ivanova (2009) notes "Finding connections and interactions between the past and the present, with the specifications of the homeland, with the manners and the interests of the generations, with the role of the games and folk works in movements provokes lasting interest and ambition for unfolding and unrolling the personal constructive potential" (p.128).

Competencies are also designed to be directly related to the key competences for Lifelong learning and they point at the perspective in child development.

\section{Research methods}

To substantiate the model for building social competences in the teaching of environmental science, first an analysis of the new curricula around the world from 2016 is performed. The goals and the expected results in them are determined, related to the social competencies of the students.

At the next stage of the research, the emotional-value elements are determined, which are emphasized in the separate sections and topics.

The integrative interactions with other subjects are determined.

The methodological forms used for effective building of social competencies in education around the world are substantiated.

\section{Research results and discussion}

Areas of competence in the curricula are one of the new aspects therein. In each of the indicated areas, a set of competencies has been defined as expected results. They are consistent with the age capacities of students in first grade, excluding memorization and mechanical reproduction, suggesting the involvement of the child at a cognitive level. This child is able to: describe, give examples, list, tell, identify, indicate, explain, know, and connect. In the curriculum for first grade and second grade the following areas aimed at developing social competence are included:

- Homeland - viewing the family, school and birthplace as communities; rights and responsibilities of the child therein.

- Man and Environment - orientation in the most significant natural and social sites in the natal place, safe behaviour of the child and tolerant relationships.

- National and Cultural Heritage - knowledge of national symbols of the Republic of Bulgaria, official and domestic holidays.

- Man and Healthy Lifestyle - knowledge of the basic requirements for a healthy lifestyle and environmental protection.

Decomposing the learning objectives into the approved model

The curriculum presupposes the decomposition of the goals of the training into knowledge, skills and competencies, in their unity. The peculiarity of forming social competence in the primary school age in the approved model is the inclusion of an emotional and values related aspect when setting goals without which the learning process would be incomplete. This component has the following contents in the individual sections:

My family

Knowledge, skills, and competencies: Codification and enrichment of children's views of family as a community and its significance for each person; understanding the responsibilities of the family members; naming and describing family holidays and awareness of their role in family togetherness. 
The emotional and values related aspect - The formation of a value attitude towards the cooperative family, to build a sense of belonging and empathy, to comprehend the role of family traditions and holidays for family togetherness.

My school

Knowledge, skills, and competencies: Awareness of the school as an institution and community; summarizing the ideas about the work of people at school and about the work of the student; understanding the rights and obligations of the student at school. The emotional and values related aspect -The formation of a value attitude towards the school as an institution and learning as a main activity, respect for the work of everyone in school.

My day

Knowledge, skills, and competencies: Introduction to the concept of a daily routine and its significance; awareness of the need to follow a daily routine; the formation of skills for planning the day with alternating mandatory activities and responsibilities with favourite activities and understanding them as a condition for success. The emotional and values related aspect - Creating satisfaction and the need for good organization of the day.

In the street

Knowledge, skills, and competencies: mastering the basic rules for safe traffic and behaviour in the street; assessing the safe places on the road and the behaviour of participants in traffic; recognizing situations that endanger security and life; using a map-scheme of the settlement as a source of knowledge. The emotional and values related aspect - The formation of skills for the observance of discipline on the road and responsibility for one's own behaviour, as well as intolerance towards violators of safety rules.

Rights and obligations of students

Knowledge, skills, and competencies: Understanding the relationship between the rights and obligations of the student in the family and at school; the formation of skills for the assessment and self-assessment of behaviour of others and their own behaviour, according to the rights and obligations of the student at school and in the family; education in the spirit of tolerant attitude when communicating with the different (children with special educational needs, children of another race or different religions).

The emotional and values related aspect - The acceptance of the rights and obligations in the family and in the school as a condition for understanding and mutual respect.

My rights and obligations

Knowledge, skills, and competencies: Getting acquainted with the rights and obligations of the student in the family and at school; the formation of knowledge and skills for correlating the rights and obligations of the student with their own behaviour and developing skills for self-assessment; the formation of skills for showing a tolerant and adequate attitude in communicating with the different (children with special educational needs, children of another race or different religions).

The emotional and values related aspect - The acceptance of the rights and obligations in the family and in the school as socially significant and important.

My native town or village

Knowledge, skills, and competencies: The systematization and enrichment of the idea of the settlement in which they live - town, village; acquisition of knowledge about the role of the homeland in Bulgaria; the formation of skills for pointing and telling about important public buildings and landmarks of the settlement; using a map-diagram of the settlement as a source of knowledge. The emotional and values related aspect - The formation and development of affection and love for the homeland, pride and responsibility for it.

Safe at home and out of home

Knowledge, skills, and competencies: Increasing knowledge about safety behaviour and risky behaviour as two mutually exclusive lines of behaviour; mastering the rules of conduct that prevent them from falling into a risky situation and developing skills to rely on them; forming an attitude of concern for health and safety; the assessment of rules of conduct as a factor for health protection. The emotional and values related aspect - The formation of respect and acceptance with a passion and a sense of dignity 
for the rules for proper behaviour in the residential environment and in nature. Being proud of his/her disciplined behaviour.

Pedagogical technology for building social competencies in Environmental Science teaching

When developing the pedagogical technology for building social competencies in the Environmental Science teaching, a systematic and pedagogical approach was used which allows for the educational process to be designed as a system. The main elements of this system are:

Teaching objectives - As part of the training objectives of building social competencies focused on communities whose member is the student:

- family and genus;

- school class and school;

- citizen of settlement;

- citizen of the Republic of Bulgaria.

Integrative interactions in enriching existing ideas and new concepts

The formation of social competencies in the Environmental Science has an integrative character and covers the entire educational process. The educational content that develops and interprets them includes:

- The consideration of natural and public sites in the homeland also set in other curricula seasonal changes, features of the homeland - nature, labour activity, landmarks, holidays and rituals, relationships, healthy lifestyle.

- Mastering cognitive strategies, which are an element of teaching in other subjects - to observe, compare, group, connect, systematize, and summarize. The new learning content is visualized in thematic development, stages, accents, characteristics. The new concepts are presented in accordance with the life experience of the students and this allows them to easily reach their generalization and systematization.

Wide application of visual strategies

The age peculiarities of the students require an emphasis on the visual supports which cover the considered educational content. By using the model of the mind map in defining basic concepts, visual supports are created that are much closer to the child, for a better understanding and comprehension of the otherwise abstract nature of each concept.

Creating and enriching models for cognitive activity

This idea is realized through various permanent sections in the learning process: "Discover yourself", "Who is right", "I already know" and so on. Their multiplied use makes it possible to master a thought strategy to consolidate and become sustainable. This allows subsequent upgrading and application of the model on a new level or to other areas of knowledge.

Methodical dynamics and diversity - in the development of the technology, this idea is represented by providing diversity and saturation of the teaching process. The organizational forms that are envisaged include, in addition to the traditional ones, the work on a school project which motivates the students for higher activity and teamwork. The designed methods for implementing the technology are diverse storytelling, conversation, consideration, description, explanation, modelling, situating, independent work, discussion, mind map and much more, including games and entertaining.

In the designed pedagogical technology, an important didactic function is performed by the separate rubrics, through which the sustainable assimilation of various cognitive strategies in the process of Environmental Science teaching and the formation of transferable skills is guaranteed. The section "Discover yourself" requires an analysis of various situations in which it is necessary to solve a problem through the transformation and practical application of acquired knowledge. The role of independent analysis and assessment in this section is to strengthen the cognitive abilities of the first-grader, to direct them to search for dependencies and relations. The "Discussion" section reveals different points of view on the studied objects, processes, phenomena and relationships. The Discussion section presents both conflicting opinions and those that are not mutually exclusive. It gives students the opportunity to express their views, compare them with the opinions of others and develop them. In this way, they learn to listen, to accept different opinions and to argue their own. The "I already know" section has summarizing functions. Through appropriate visualization of the content of the new concepts in the 
lesson, the essential and accessible for the indications for the first-graders have been revealed. The visualization in the rubric follows the model of the famous "Mind Maps", in which the central concept with branches presents its various characteristics. In addition to summarizing and systematizing new knowledge, this section aims to prepare and build skills for discovering the essential features of a concept and the future self-creation of Mind Maps. This takes place in a supportive and creative environment and encourages students to be creative.

The presented pedagogical technology is developed in the process of learning around the world through all groups of teaching methods - verbal, visual, practical, interactive and game. Their combination and complementarity is a condition for the successful implementation of the technology. The methodological diversity of the envisaged activities and tasks provides dynamics and high cognitive saturation of the training.

\section{Results}

As a result of the performed analysis of the teaching kits in Environmental Science for first and second grade, the following indicators of the applied technology for the formation of social competencies can be distinguished and indicated:

- Emphasis is placed on the commented value aspect, which is invariably present in each of the topics in the Environmental Science teaching. Thus, as a result, the necessary relationships are reached which are the basis of competencies.

- The formulations of the topics of the individual works place emphasis on the student's activity: for example "Introducing my family", "We meet our school", etc. Thus, the topic presupposes the active participation of the child and prevents the content-informational focus on the learning content as an end in itself. The formulations of the topics of the lesson units refer to the direction of the cognitive activity of the students, putting the child in an active position. When setting the topic in the course of the lesson, the motivating functions of the proposed formulations are used by using a verb in $1^{\text {st }}$ person singular.

- Wide inclusion of cognitive tasks for finding patterns, relationships and interrelationships. The function of these tasks is to systematize the existing ideas in order to enrich and summarize the children's experience in accordance with the leading goals and objectives. They are carried out through a variety of activities by students - marking, colouring, correlating, connecting, etc. After their implementation, a comment must be made, which aims to include new concepts in the student's vocabulary, as well as the development of speech, the ability to express and justify.

\section{Conclusion}

Social competencies are formed in the conditions of active learning, putting the student in various learning situations which give him the opportunity for active acquisition of knowledge and for optimal individual development.

Pedagogical technology helps the students to make their own observations and reflections and independently reach knowledge about the human communities.

The implemented technology develops the ability to listen and objectively assess different points of view, as well as the ability to express and defend their own position.

In the process of teaching in Environmental Science, an opportunity for project activities and teamwork, to create practical products by students - project books, albums, files, panels etc is provided.

The training is aimed at building objective assessment and self-assessment.

\section{References}

Bostandzhiev, R. (2011) Social and emotional competence - new perspective for education and social work. Contemporary Humanities No.1.Burgas: Free University Publishing House,

Ivanova V. (2009) The Bulgarian Folk Games into the Physical Education of Children from Primary School. Skopie, Macedoniya: Physical Education.

Levterova, D., Stamatov, R., Sariyska, Sv., Goranova, M. (2013) Identity and Social Competence. Plovdiv: Paisiy Hilendarski University Publishing House.

Levterova, D. (2009) Social Competence: P. I - IV.Plovdiv: Paisiy Hilendarski University Publishing House.

Petrova, V. Janakieva, E. Parvanova, J. Stoyanova, R. (2016) Environmental Science $1^{\text {st }}$ grade. Sofia: Bulvest 2000.

Petrova, V. Janakieva, E. Parvanova, J. Stoyanova, R. (2016) Environmental Science $2^{\text {nd }}$ grade. Sofia: Bulvest 2000.

Stamatov, R., S. Sariyska et al. (2015) Social Competence and Creativity Manual in Pictures. Plovdiv: Blakom Publishing House. 